\title{
CONSISTENCY OF LAW ENFORCEMENT PRACTICE IN MATTERS OF DEVIATION FROM THE PRINCIPLE OF EQUALITY OF THE SPOUSES' SHARES IN THEIR COMMON PROPERTY
}

\author{
Natalia A. Ablyatipova \\ Russian State University of Justice (Crimean Branch), Simferopol, Russian Federation
}

Introduction: the issues of the division of the jointly acquired property of spouses do not lose their relevance. As a general rule, in the absence of an agreement between the spouses, the division is carried out in court based on the legally established presumption of equality of shares, regardless of the method of participation in the formation of joint property. However, this principle is not absolute and the court has the right to deviate from the principle of equality by increasing the share of one of the spouses. Meanwhile, the possibility of increasing the share in the marital property is interpreted ambiguously in law enforcement, and the incorrect interpretation of the norm is revealed. In this regard, the author sets the goal: to summarize the approaches developed by the judicial practice on this issue, to identify and analyze the grounds for deviation from the principle of equality of shares in the division of property of spouses. Results: the reasons for the increase in the marital share are investigated, the problems of determining the criteria are identified, and the inconsistency of court decisions in similar cases when considering the categories "child's interest" and "spouse's interest" is established. Conclusions: based on the analysis of the legislation and materials of judicial practice, the problems of applying the grounds for derogating from the equality of the shares of spouses in the division of jointly acquired property and the ambiguity of the law enforcement are highlighted. Based on the results of the work, the author has developed some practical proposals and recommendations for improving the legislation.

Key words: property of spouses, division of common property, an increase of share, interest of the child, deviation from the principle of equality of shares of spouses, judicial practice.

Citation. Ablyatipova N.A. Consistency of Law Enforcement Practice in Matters of Deviation from the Principle of Equality of the Spouses' Shares in Their Common Property. Legal Concept = Pravovaya paradigma, 2021, vol. 20, no. 3, pp. 116-124. (in Russian). DOI: https://doi.org/10.15688/lc.jvolsu.2021.3.18

\section{СИСТЕМНОСТЬ ПРАВОПРИМЕНИТЕЛЬНОЙ ПРАКТИКИ В ВОПРОСАХ ОТСТУПЛЕНИЯ ОТ НАЧАЛА РАВЕНСТВА ДОЛЕЙ СУПРУГОВ В ИХ ОБЩЕМ ИМУЩЕСТВЕ}

\author{
Наталья Айдеровна Аблятипова \\ Российский государственный университет правосудия (Крымский филиал), \\ г. Симферополь, Российская Федерация
}

Введение: вопросы раздела совместно нажитого имущества супругов не утрачивают своей актуальности. По общему правилу, при отсутствии соглашения супругов раздел осуществляется в судебном порядке на основе установленной законодательно презумпции равенства долей независимо от способа участия в формировании совместной собственности. Однако указанный принцип не является абсолютным и суд вправе отступить от начала равенства, увеличив долю одного из супругов. Между тем возможность увеличения доли в супружеском имуществе трактуется в правоприменении неоднозначно, выявляется неверное толко- 
вание нормы. В связи с этим автором поставлена цель: обобщить выработанные судебной практикой подходы по данному вопросу, выявить и проанализировать основания отступления от принципа равенства долей при разделе имущества супругов. Результаты: исследованы основания увеличения супружеской доли, выявлены проблемы определения критериев, установлены несоответствия в судебных решениях по схожим делам при рассмотрении категорий «интерес ребенка» и «интерес супруга». Выводы: на основе анализа законодательства и материалов судебной практики выделены проблемы применения оснований отступления от равенства долей супругов при разделе совместно нажитого имущества и неоднозначность правоприменения. По результатам работы, автором выведены практические предложения и рекомендации по совершенствованию законодательства.

Ключевые слова: имущество супругов, раздел общего имущества, увеличение доли, интерес ребенка, отступление от принципа равенства долей супругов, судебная практика.

Цитирование. Аблятипова Н. А. Системность правоприменительной практики в вопросах отступления от начала равенства долей супругов в их общем имуществе // Legal Concept = Правовая парадигма. - 2021. T. 20, № 3. - C. 116-124. - DOI: https://doi.org/10.15688/lc.jvolsu.2021.3.18

\section{Введение}

Семейное законодательство закрепляет законный режим имущества супругов и подчеркивает их равные права на общее имущество независимо от способа участия в формировании совместной собственности. Данное правило лежит в основе владения, пользования и распоряжения супружеским имуществом, а также устанавливает особый порядок его раздела. Основной целью последнего является выделение долей супругов и прекращение общей совместной собственности. В силу п. 1 ст. 39 Семейного кодекса Российской Федерации (далее - СК РФ) [20] при разделе общего имущества супругов и определении долей в этом имуществе доли супругов признаются равными, если иное не установлено договором между супругами. Следовательно, при отсутствии брачного договора доли супругов определяются на основании принципа равенства долей.

При этом закон допускает раздел имущества как добровольно на основании соглашения супругов, так и принудительно в судебном порядке. Особое значение приобретает способ раздела при реализации правомочий супругов изменить размер доли, установленной законодателем. При добровольном разделе имущества и отсутствии спора между супругами они вправе заключить соглашение о разделе совместно нажитого имущества и самостоятельно определить принадлежащие им доли без соблюдения принципа их равенства. Также в судебной практике довольно часто встречаются заявленные требования истца об увеличении размера доли, против которых ответчик не возражает [15]. Указанное значительно упрощает процедуру раздела и подчеркивает диспозитивность отдельных норм семейного права.

В случае недостижения соглашения раздел общего имущества производится судом по требованию супругов, основываясь на установленной презумпции равенства долей. Тем не менее, как следует из п. 2 ст. 39 СК РФ, принцип равенства долей супругов не является абсолютным и суд вправе отступить от начала равенства долей в общем имуществе супругов при наличии значимых обстоятельств. При этом нормам действующего законодательства предусмотрено право, но не обязанность суда при разрешении требований о разделе имущества супругов отступить от равенства их долей в общем имуществе. Полагаем, необходимо рассмотреть особенности оснований отступления от начала равенства долей супругов и проанализировать проблемы правоприменения.

\section{Проблемы определения интересов детей как основания отступления от начала равенства долей супругов в их общем имуществе}

Анализ п. 2 ст. 39 СК РФ позволяет разделить основания отступления от равенства долей супругов условно на две группы. При этом следует отметить, что указанные группы оснований не должны существовать одновременно, закон не требует их совокупности. В первой группе закон отметил интересы де- 
тей, не достигших совершеннолетия. Отступление от начала равенства долей супругов в их общем имуществе, исходя из интересов несовершеннолетних детей, согласуется также с конституционным принципом, закрепленным в ч. 2 ст. 7, ч. 1 ст. 38 Конституции Российской Федерации [2].

Обратим внимание, что в СК РФ при указании на интересы несовершеннолетних детей не установлены требования, чтобы это были общие дети супругов. Следовательно, при разделе общего имущества супругов могут быть приняты во внимание интересы несовершеннолетних детей одного из супругов [8, с. 28]. Сложно не согласиться с данной позицией, что подтверждается немногочисленной практикой, хотя в обзорах и отдельных определениях ВС РФ в последние годы отображается указание именно на общих детей.

Безусловно, защита интересов детей при расторжении брака имеет важное значение и направлена на сохранение условий, необходимых для нормального полноценного развития и обучения. Ошибочное толкование указанной нормы приводит к тому, что заявители считают достаточным для удовлетворения их требований об увеличении доли указания в обосновании факта совместного проживания с детьми. Например, истец просит отступить от равенства долей супругов на основании факта проживания с ней двоих детей [18], в другом деле бывшая жена указывает на беременность, воспитание несовершеннолетнего ребенка и отсутствие участия отца в воспитании и содержании ребенка [9]. Как правило, суды отказывают в удовлетворении таких требований обосновано [4; 16]. Например, в решении от 16 января 2020 г. по делу № 2-141/ 2019 справедливо отмечено, что наличие у сторон от брака пятерых детей, четверо из которых являются несовершеннолетними, в силу закона не является основанием для увеличения доли супруга, совместно с ними проживающего после прекращения брака. Законом предусмотрены иные гарантии защиты прав и законных интересов такого родителя в виде права требований уплаты алиментов на содержание детей от отдельно проживающего родителя [19].

Однако встречается противоположная практика. Например, из материалов дела от
16 июля 2020 г. № 2-516/2020 прослеживается, что согласно заключенному между родителями соглашению об определении места жительства детей, они должны были проживать с отцом на протяжении года, а потом они должны были переехать к матери. Срок действия мирового соглашения истек, однако дети продолжают проживать и находятся на полном иждивении отца. На основании свидетельских показаний подтверждено, что мать свои родительские обязанности по содержанию детей не выполняет. Важно отметить, что истцом в данном деле выступал финансовый управляющий в силу введенной процедуры банкротства (реализации имущества матери). Мать в заседание не явилась, и суд не уточнил порядок ее участия в жизни детей. Однако указанные обоснования суд счел достаточными и, учитывая интересы несовершеннолетних детей, которые остались проживать с отцом, неучастие матери детей в их содержании увеличивает долю ответчика в праве собственности на автомобиль до 3/4 доли, за истцом суд признает право собственности на 1/4 доли [11].

Следовательно, отсутствует единое понимание соблюдения интересов детей при разделе имущества их родителей. Как пояснил Верховный Суд еще в 2019 г. в своем Обзоре (п. 14): «Наличие общего несовершеннолетнего ребенка не является безусловным основанием для отступления от начала равенства долей при разделе имущества супругов» [3]. Проживание с одним из супругов их общего несовершеннолетнего ребенка само по себе не является достаточным основанием для отступления от принципа равенства долей супругов в общей собственности, поскольку родитель, проживающий отдельно от ребенка, обязан участвовать в его воспитании и содержании (в том числе уплачивать алименты на содержание ребенка). Поддерживая аналогичную позицию, суды отмечают, что бывшие супруги находятся в равном положении относительно своего отношения к соблюдению имущественных интересов несовершеннолетних детей [5].

Также в качестве обоснований своих требований заявители часто привязывают возможность увеличения доли с целью соблюдения жилищных прав детей. Так, истец 
заявила требования о передаче ей в собственность $2 / 3$ доли на земельный участок и жилой дом и признании права собственности по $1 / 2$ доли на остальное имущество и долговые обязательства, тем самым просит отступить от принципа равенства долей супругов только в отношении земельного участка и жилого дома. В качестве мотивировки своих требований она указывает, что несовершеннолетний ребенок проживает с ней и другого жилого помещения в собственности у ребенка нет. Суд, принимая решение, отметил, что отсутствие у ребенка в собственности жилого помещения не относится к основаниям отступления от принципа равенства долей, поскольку дети не имеют права собственности на имущество родителей [17]. В решении Лермонтовского городского суда от 9 июля 2020 г. по делу № 2-20/2020 суд отмечает отсутствие обстоятельств для отступления с указанием на то, что жилищные права детей по отношению к имуществу родителей сохраняются, их содержание обеспечивается алиментными обязательствами [13].

Анализ судебной практики выявил, что в большинстве случаев суды приходят к выводу об отсутствии доказательств, подтверждающих наличие исключительных существенных обстоятельств, свидетельствующих о необходимости учета интересов несовершеннолетних детей при разделе имущества супругов и отступления от принципа равенства долей супругов в общем имуществе. Однако закон не содержит перечня заслуживающих внимания интересов несовершеннолетних детей, с учетом которых суд вправе отступить от начала равенства долей супругов в общем имуществе. Указанные причины (обстоятельства) устанавливаются в каждом конкретном случае с учетом представленных сторонами доказательств.

В этой связи следует отметить необходимость представления серьезных, веских доказательств того, что наличествует основание для отступления от принципа равенства долей супругов. Так как дети не наделены самостоятельным правом на имущество родителей, в решении суда должно быть отображено, каким именно образом соблюдаются интересы детей данным отступлением.

Положительная практика не обширна и чаще направлена на соблюдение интересов детей-инвалидов поддерживать материальный уровень жизни с учетом диагноза. Например, исходя из интересов несовершеннолетнего ребенка, истец просила увеличить размер ее доли. В качестве доказательства отмечена инвалидность ребенка, необходимость дорогостоящего лечения, отсутствие иного жилого помещения. Также отмечено, что раздел имущества супругов неизбежно влечет ухудшение материального положения их дочери, поскольку то имущество, которым она раньше могла владеть и пользоваться, становится для нее недоступным или доступ к нему существенно ограничивается, что приобретает особое значение для нее как инвалида, нуждающегося по состоянию здоровья в дополнительном уходе, требующем соответствующих материальных затрат [12].

Таким образом, судебная практика показывает, что в рамках разрешения вопроса об интересах ребенка при разделе имущества супругов необходимо учитывать уровень материального положения ребенка во взаимосвязи с состоянием его здоровья, наличием потребности в дополнительном уходе, определенных условиях проживания, поскольку ухудшение материального положения ребенка в таком случае влечет за собой негативные последствия для его жизни и здоровья [1, c. 102].

\section{Соблюдение интереса одного из супругов как основание отступления от принципа равенства долей супругов}

Вторая группа оснований базируется на заслуживающем внимания интересе одного из супругов, в частности, в случаях, если другой супруг не получал доходов по неуважительным причинам или расходовал общее имущество супругов в ущерб интересам семьи.

Как отражено в п. 17 Постановления Пленума Верховного Суда РФ от 5 ноября 1998 г. № 15 «О применении судами законодательства при рассмотрении дел о расторжении брака» [6], под такими интересами следует понимать не только случаи, когда супруг без уважительных причин не получал доходов либо расходовал общее имущество супругов в ущерб интересам семьи, но и когда один из супругов по состоянию здоровья или по иным, не зависящим от него обстоятельствам, ли- 
шен возможности получать доход от трудовой деятельности.

Тем не менее практика отражает неправильное толкование норм материального права заявителями, которые часто связывают интерес супруга, указанный в п. 2 ст. 39 СК РФ, и способы наращивания совместного имущества. Так, истец в обоснование увеличения своей доли указывает на то, что спорная квартира, равно как и спорный автомобиль были приобретены на ее личные средства, поскольку в период брака она была постоянно трудоустроена и получала заработную плату [14]. Подчеркнем, что закон не связывает возникновение режима общей собственности супругов на такой доход от того, в какой форме он может быть получен.

В деле № 2-362/2020 от 30 июля 2020 г. заявитель указала, что основанием для отступления от начала равенства долей супругов в общем имуществе является то обстоятельство, что в период брака бывший супруг официально не работал, брался изредка за временную подработку [10]. В подтверждение указанных доводов представлена трудовая книжка. Между тем, по мнению суда, отсутствие записей в трудовой книжке само по себе не свидетельствует о том, что супруг не получал дохода и не вкладывал никаких средств в семейный бюджет. Такая практика довольно обширна. Отметим, что, как правило, суды верно и обоснованно отказывают в увеличении доли по данным требованиям.

Следовательно, для удовлетворения требования необходимо предоставить доказательства отсутствия заработка и (или) иного дохода без уважительных причин либо расходования общего имущества в ущерб интересам семьи, что, как правило, относится к затрудненным фактам. Перечень действий другого супруга, которые являются основанием для снижения размера его доли, открыт и может быть дополнен исходя из конкретной ситуации. Как правило, суды признают обоснованными доказательства причинения ущерба имущественным интересам семьи (неоднократные штрафы за хулиганство, алкоголизм, наркомания, игровая зависимость), упуская сферу личных неимущественных отношений (недостойное поведение, неуважительное отношение к членам семьи).
Полагаем, очевидна потребность дальнейшего совершенствования указанных норм, в том числе разъяснений Верховного суда касательно общих правил толкования материальных норм для единого правоприменения. В Проекте Федерального закона № 835938-7 «О внесении изменений в отдельные законодательные акты Российской Федерации» [7], в частности, предусмотрен механизм дополнительной защиты одного из супругов в случае недобросовестного поведения при распоряжении супружеским имуществом. Предлагается расширить п. 2 ст. 39 СК РФ возможностью отступления от долей и соответственно уменьшению доли того из супругов, который совершал сделки по отчуждению общего имущества на невыгодных условиях без согласия другого супруга. Данное основание может быть реализовано только при условии, что к указанным сделкам не применялись последствия недействительности по требованию второго супруга. Полагаем, такое расширение нормы лишь усложнит правоприменительную практику, так как необходимо будет доказать не только отсутствие согласия, но и невыгодные для семьи условия заключения сделки.

\section{Выводы}

Исходя из вышеизложенного, следует подчеркнуть:

- при рассмотрении споров супругов о разделе совместно нажитого имущества следует разграничивать требования об увеличении доли супруга в целях соблюдения интересов детей и одного из супругов, если другой супруг не получал доходов по неуважительным причинам или расходовал общее имущество супругов в ущерб интересам семьи;

- дети не наделены самостоятельным правом на имущество родителей, наличие общего несовершеннолетнего ребенка не является безусловным основанием для отступления от начала равенства долей при разделе имущества бывших супругов;

- интересы ребенка, которые учитываются при отступлении от принципа равенства долей супругов, подразумевают наличие системы обстоятельств, в которой в зависимость от возможности сохранения прежнего материального положения ребенка ставится воз- 
можность реализации его личных неимущественных прав, сохранение прежнего уровня жизни; также имеет значение то обстоятельство, что в противном случае присутствует риск существенного снижения уровня жизни ребенка [1, с. 106];

- следует учитывать, что увеличение доли одного из супругов должно распространяться не на все совместно нажитое имущество, а только на то, в использовании которого имеется интерес несовершеннолетнего ребенка или супруга;

- для изменения имущественного положения супругов, которое законодатель устанавливает в качестве общего правила, отступления от принципа равенства долей супругов требуется наличие исключительных обстоятельств, обоснованных надлежащими доказательствами, в то время как законодательство нуждается в совершенствовании для единой практики правоприменения и недопущения субъективизма при принятии различных решений в схожих ситуациях.

\section{СПИСОК ЛИТЕРАТУРЫ}

1. Аблятипова, Н. А. Проблемы реализации имущественных прав супругов, связанные с прекращением брака / Н. А. Аблятипова, А. А. Кравцова // Вопросы российского и международного права. - 2019. - Т. 9, № 7А. - С. 100-109.

2. Конституция Российской Федерации (принята всенародным голосованием 12.12.1993 с изменениями, одобренными в ходе общероссийского голосования 01.07.2020) // Российская газета. 2020. - Июль (№ 14).

3. Обзор судебной практики Верховного Суда РФ № 3 (2019) (утв. Президиумом Верховного Суда РФ 27.11.2019 г.) // Бюллетень Верховного Суда Российской Федерации. - 2020. - Апр. (№ 4).

4. Определение СК по гражданским делам Верховного Суда РФ от 26.05.2020 № 18-КГ20-15. Электрон. текстовые дан. - Режим доступа: https:// www.garant.ru/ (дата обращения: 01.04.2021). - Загл. с экрана.

5. Определение СК по гражданским делам Третьего кассационного суда общей юрисдикции от 15.06.2020 по делу№ 8Г-5699/2020[88-6563/2020]. Электрон. текстовые дан. - Режим доступа: https:// www.garant.ru/(дата обращения: 01.04.2021). - Загл. с экрана.

6. Постановление Пленума Верховного Суда РФ от 5 ноября 1998 г. № 15 «О применении судами законодательства при рассмотрении дел о расторжении брака» // Российская газета. - 1998. - 18 нояб.

7. Проект Федерального закона № 835938-7 «О внесении изменений в отдельные законодательные акты Российской Федерации» (ред., внесенная в ГД ФС РФ, текст по состоянию на 14.11.2019). Электрон. текстовые дан. - Режим доступа: https:// sozd.duma.gov.ru/bill/835938-7 (дата обращения: 01.04.2021). - Загл. с экрана.

8. Расторгуева, А. А. Раздел имущества между супругами и наследниками: правовые аспекты / А. А. Расторгуева. - М. : Редакция «Российской газеты», 2019. - 143 c.

9. Решение Верхнепышминского городского суда (Свердловская область) № 2-205/2020 2-205/ 2020(2-2733/2019;) M-2350/20192-2733/2019 M-2350/ 2019 от 12.02.2020 по делу № 2-205/2020 // Судебные и нормативные акты РФ. - Электрон. текстовые дан. - Режим доступа: http://sudact.ru/regular/doc/ Wiux7RCpAxdj/ (дата обращения: 01.04.2021). - Загл. с экрана.

10. Решение Ессентукского городского суда (Ставропольский край) № 2-362/2020 2-362/2020 M80/2020 М-80/2020 от 30.07.2020 г. по делу № 2-362/ 2020 // Судебные и нормативные акты РФ. - Электрон. текстовые дан. - Режим доступа: http:// sudact.ru/regular/doc/Tg2NEDLme71W/ (дата обращения: 01.04.2021). - Загл. с экрана.

11. Решение Зейского районного суда (Амурская область) № 2-516/2020 2-516/2020 М-472/2020 М-472/2020 от 16.07.2020 г. по делу № 2-516/2020 // Судебные и нормативные акты РФ. - Электрон. текстовые дан. - Режим доступа: http://sudact.ru/ regular/doc/QOpTrYvGaEdC/ (дата обращения: 01.04.2021). - Загл. с экрана.

12. Решение Кисловодского городского суда (Ставропольский край) № 2-1842/2019 2-1842/ 2019 M-1605/2019 M-1605/2019 от 26.11.2019 г. по делу № 2-1842/2019 // Судебные и нормативные акты РФ. - Электрон. текстовые дан. - Режим доступа: http://sudact.ru/regular/doc/O3ENfzOsvRLC: (дата обращения: 01.04.2021). - Загл. с экрана.

13. Решение Лермонтовского городского суда (Ставропольский край) № 2-20/2020 2-20/2020 (2-331/ 2019;) М-331/20192-331/2019 М-331/2019 от 9 июля 2020 г. по делу № 2-20/2020 // Судебные и нормативные акты РФ. - Электрон. текстовые дан. - Режим доступа: http://sudact.ru/regular/doc/VqyJNXjGorJn/ (дата обращения: 01.04.2021). - Загл. с экрана.

14. Решение Люберецкого городского суда (Московская область) № 2-2205/2020 2-2205/2020 M$1408 / 2020$ M-1408/2020 от 07.09.2020 г. по делу № 22205/2020 // Судебные и нормативные акты РФ. Электрон. текстовые дан. - Режим доступа: http:// sudact.ru/regular/doc/EdmDnssnFmmT/ (дата обращения: 01.04.2021). - Загл. с экрана. 
15. Решение Пластского городского суда (Челябинская область) № 2-75/2020 2-75/2020 М-724/ 2019 М-724/2019 от 28.05.2020 по делу № 2-75/2020 / / Судебные и нормативные акты РФ. - Электрон. текстовые дан. - Режим доступа: http://sudact.ru/ regular/doc/qS6RhQeDruV5/ (дата обращения: 01.04.2021). - Загл. с экрана.

16. Решение Промышленного районного суда г. Ставрополя (Ставропольский край) № 2-277/2020 2-277/2020(2-6826/2019;) M-6463/20192-6826/2019M6463/2019 от 17.02.2020 по делу № 2-277/2020 // Судебные и нормативные акты РФ. - Электрон. текстовые дан. - Режим доступа: http://sudact.ru/ regular/doc/F3A5op6GQwxc/ (дата обращения: 01.04.2021). - Загл. с экрана.

17. Решение Светлогорского городского суда (Калининградская область) № 2-16/2020 2-16/2020(2660/2019;) M-498/2019 2-660/2019 M-498/2019 от 13 мая 2020 г. по делу № 2-16/2020 // Судебные и нормативные акты РФ. - Электрон. текстовые дан. - Режим доступа: http://sudact.ru/regular/doc/ v0usvCX6GXlH/ (дата обращения: 01.04.2021). - Загл. с экрана.

18. Решение Соль-Илецкого районного суда (Оренбургская область) № 2-305/2020 2-305/2020 M103/2020 М-103/2020 от 29.07.2020 по делу № 2-305/ 2020 // Судебные и нормативные акты РФ. - Электрон. текстовые дан. - Режим доступа: http:// sudact.ru/regular/doc/PGmU265Z2aQf/ (дата обращения: 01.04.2021). - Загл. с экрана.

19. Решение Центрального районного суда г. Симферополя (Республика Крым) № 2-141/2019 22805/2018 2-8/2020 2-8/2020(2-141/2019;2-2805/ 2018;) М-2737/2018 M-2737/2018 от 16.01.2020 по делу № 2-141/2019 // Судебные и нормативные акты РФ. Электрон. текстовые дан. - Режим доступа: http:// sudact.ru/regular/doc/Ks0XPWiS1b6W/ (дата обращения: 01.04.2021). - Загл. с экрана.

20. Семейный кодекс Российской Федерации от 29.12.1995 № 223-Ф3 (ред. от 04.02.2021) // Российская газета. - 1996. - 27 янв. (№ 17).

\section{REFERENCES}

1. Abliatipova N.A., Kravtsova A.A. Problemy realizatsii imushchestvennykh prav suprugov, sviazannye s prekrashcheniem braka [Problems of the Implementation of Property Rights of Spouses Associated with the Termination of Marriage] Voprosy rossiiskogo i mezhdunarodnogo prava [Matters of Russian and International Law], 2019, vol. 9, no. 7A, pp. 100-109.

2. Konstitutsiia Rossiiskoi Federatsii (priniata vsenarodnym golosovaniem 12.12.1993 sizmeneniiami, odobrennymi $\mathrm{v}$ khode obshcherossiiskogo golosovaniia 01.07.2020) [The Constitution of the Russian Federation]. Rossiiskaia gazeta, 2020, July (no. 14).

3. Obzor sudebnoi praktiki Verkhovnogo Suda RF №3 (2019) (utv. Prezidiumom Verkhovnogo Suda RF 27 noiabria 2019 g.) [Review of Judicial Practice of the Supreme Court of the Russian Federation No. 3 (2019) (Approved by the Presidium of the Supreme Court of the Russian Federation on November 27, 2019)]. Biulleten Verkhovnogo Suda Rossiiskoi Federatsii [Bulletin of the Supreme Court of the Russian Federation], 2020, April, no. 4.

4. Opredelenie SK po grazhdanskim delam Verkhovnogo Suda RF ot 26 maia 2020 g. №18$K G 20-15$ [Determination of the IC in Civil Cases of the Supreme Court of the Russian Federation Dated May 26, 2020 No. 18-KG20-15]. URL: https:// www.garant.ru/ (accessed 1 April 2021).

5. Opredelenie SK po grazhdanskim delam Tretego kassatsionnogo suda obshchei iurisdiktsii ot 15 iiunia 2020 g. po delu №8G-5699/2020 (886563/2020) [Determination of the IC in Civil Cases of the Third General Jurisdiction Court of Cassation Dated June 15, 2020 in Case No. 8Г-5699/2020 (886563/2020)]. URL: https://www.garant.ru/ (accessed 1 April 2021).

6. Postanovlenie Plenuma Verkhovnogo Suda RF ot 5 noiabria 1998 g. №15 “O primenenii sudami zakonodatelstva pri rassmotrenii del o rastorzhenii braka" [Resolution of the Plenum of the Supreme Court of the Russian Federation of November 5, 1998. No. 15 "On the Application of Regislation by Courts When Considering Cases of Divorce"]. Rossiiskaia gazeta, 1998, Nov. 18.

7. Proekt Federalnogo zakona №835938-7 "O vnesenii izmenenii $v$ otdelnye zakonodatelnye akty Rossiiskoi Federatsii» (red., vnesennaia v GD FS RF, tekst po sostoianiiu na 14.11.2019) [Draft Federal Law No. 835938-7 “On Amendments to Certain Legislative Acts of the Russian Federation" (As Amended by the State Duma of the Federal Assembly of the Russian Federation, text as of 11/14/2019)]. URL: https://sozd.duma.gov.ru/bill/835938-7 (accessed 1 April 2021).

8. Rastorgueva A.A. Razdel imushchestva mezhdu suprugami i naslednikami: pravovye aspekty [Division of Property Between Spouses and Heirs: Legal Aspects]. Moscow, Rossiyskaya Gazeta, 2019, $143 \mathrm{p}$.

9. Reshenie Verkhnepyshminskogo gorodskogo suda (Sverdlovskaia oblast) № 2-205/2020 2-205/ 2020(2-2733/2019;) M-2350/20192-2733/2019 M-2350/ 2019 ot 12 fevralia 2020 g. po delu № 2-205/2020 [Decision of the Verkhnepyshminsky City Court (Sverdlovsk Region) No. 2-205/2020 2-205/2020 (22733/2019;) M-2350/2019 2-2733/2019 M-2350/2019 
dated February 12, 2020 to Case No. 2-205] Sudebnye $i$ normativnye akty RF [Judicial and Regulatory Acts of the Russian Federation]. URL: http://sudact.ru/ regular/doc/Wiux7RCpAxdj/ (accessed 1 April 2021).

10. Reshenie Essentukskogo gorodskogo suda (Stavropolskii krai) № 2-362/2020 2-362/2020 M-80/ 2020 M-80/2020 ot 30 iiulia 2020 g. po delu № 2-362/ 2020 [Decision of the Essentuki City Court (Stavropol Territory) No. 2-362/2020 2-362/2020 M-80/2020 M-80/ 2020 Dated July 30, 2020 in Case No. 2-362/2020]. Sudebnye $i$ normativnye akty RF [Judicial and regulatory acts of the Russian Federation]. URL: http:/ /sudact.ru/regular/doc/Tg2NEDLme71W/ (accessed 1 April 2021).

11. Reshenie Zeiskogo raionnogo suda (Amurskaia oblast) № 2-516/2020 2-516/2020 M-472/ 2020 M-472/2020 ot 16 iiulia 2020 g. po delu № 2-516/ 2020 [Decision of the Zeyskiy District Court (Amur Region) No. 2-516/2020 2-516/2020 M-472/2020 M472/2020 Dated July 16, 2020 in Case No. 2-516/2020]. Sudebnye $i$ normativnye akty RF [Judicial and regulatory acts of the Russian Federation]. URL: http:/ /sudact.ru/regular/doc/QOpTrYvGaEdC/ (accessed 1 April 2021).

12. Reshenie Kislovodskogo gorodskogo suda (Stavropolskii krai) № 2-1842/2019 2-1842/2019 M$1605 / 2019$ M-1605/2019 ot 26 noiabria 2019 g. po delu № 2-1842/2019 [Decision of the Kislovodsk City Court (Stavropol Territory) No. 2-1842/20192-1842/2019 M1605/2019 M-1605/2019 Dated November 26, 2019 in Case No. 2-1842/2019]. Sudebnye i normativnye akty $R F$ [Judicial and regulatory acts of the Russian Federation]. URL: http://sudact.ru/regular/doc/ O3ENfzOsvRLC: (accessed 1 April 2021).

13. Reshenie Lermontovskogo gorodskogo suda (Stavropolskii krai) № 2-20/2020 2-20/2020(2-331/ 2019;) M-331/2019 2-331/2019 M-331/2019 ot 9 iiulia 2020 g. po delu № 2-20/2020 [Decision of the Lermontov City Court (Stavropol Territory) No. 2-20/2020 2-20/ 2020(2-331/2019;) M-331/20192-331/2019 M-331/2019 Dated July 9, 2020 in Case No. 2-20/2020]. Sudebnye $i$ normativnye akty $R F$ [Judicial and regulatory acts of the Russian Federation]. URL: http://sudact.ru/ regular/doc/VqyJNXjGorJn/ (accessed 1 April 2021).

14. Reshenie Liuberetskogo gorodskogo suda (Moskovskaia oblast) № 2-2205/2020 2-2205/2020 M$1408 / 2020 \mathrm{M}-1408 / 2020$ ot 7 sentiabria 2020 g. po delu № 2-2205/2020 [Decision of the Lyubertsy City Court (Moscow Region) No. 2-2205/2020 2-2205/2020 M1408/2020 M-1408/2020 Dated September 7, 2020 in Case No. 2-2205/2020]. Sudebnye i normativnye akty $R F$ [Judicial and Regulatory Acts of the Russian Federation]. URL: http://sudact.ru/regular/doc/ EdmDnssnFmmT/ (accessed 1 April 2021).

15. Reshenie Plastskogo gorodskogo suda (Cheliabinskaia oblast) № 2-75/2020 2-75/2020 M-724/
2019 M-724/2019 ot 28 maia 2020 g. po delu № 2-75/ 2020 [Decision of the Plast City Court (Chelyabinsk Region) No. 2-75 / 2020 2-75 / $2020 \sim \mathrm{M}-724 / 2019$ M724/2019 Dated May 28, 2020 in Case No. 2-75 / 2020]. Sudebnye $i$ normativnye akty $R F$ [Judicial and regulatory acts of the Russian Federation]. URL: http:/ /sudact.ru/regular/doc/qS6RhQeDruV5/ (accessed 1 April 2021).

16. Reshenie Promyshlennogo raionnogo suda g. Stavropolia (Stavropolskii krai) № 2-277/2020 2-277/ 2020(2-6826/2019;) M-6463/20192-6826/2019 M-6463/ 2019 ot 17 fevralia 2020 g. po delu № 2-277/2020 [Decision of the Industrial District Court of Stavropol (Stavropol Territory) No. 2-277/2020 2-277/2020 (26826/2019;) M-6463/2019 2-6826/2019 M-6463/2019 Dated 17 February 2020 in Case No. 2-277/2020]. Sudebnye $i$ normativnye akty $R F$ [Judicial and regulatory acts of the Russian Federation]. URL: http:/ /sudact.ru/regular/doc/F3A5op6GQwxc/ (accessed 1 April 2021).

17. Reshenie Svetlogorskogo gorodskogo suda (Kaliningradskaia oblast) № 2-16/2020 2-16/2020(2-660/ 2019;) M-498/20192-660/2019 M-498/2019 ot 13 maia 2020 g. po delu № 2-16/2020 [Decision of the Svetlogorsk City Court (Kaliningrad Region) No. 216/20202-16/2020 (2-660/2019;) M-498/20192-660/2019 M-498/2019 Dated May 13, 2020 in Case No. 2-16/2020]. Sudebnye $i$ normativnye akty $R F$ [Judicial and regulatory acts of the Russian Federation]. URL: http:/ /sudact.ru/regular/doc/v0usvCX6GX1H/ (accessed 1 April 2021).

18. Reshenie Sol-Iletskogo raionnogo suda (Orenburgskaia oblast) № 2-305/20202-305/2020 M-103/ 2020 M-103/2020 ot 29 iiulia 2020 g. po delu № 2-305/2020 [Decision of the Sol-Iletsk District Court (Orenburg Region) No. 2-305/2020 2-305/2020 M-103/2020 M-103/ 2020 Dated July 29, 2020 in Case No. 2-305/2020]. Sudebnye i normativnye akty $R F$ [Judicial and regulatory acts of the Russian Federation]. URL: http://sudact.ru/ regular/doc/PGmU265Z2aQf/ (accessed 1 April 2021).

19. Reshenie Tsentralnogo raionnogo suda g. Simferopolia (Respublika Krym) № 2-141/2019 22805/2018 2-8/2020 2-8/2020(2-141/2019; 2-2805/ 2018;) M-2737/2018 M-2737/2018 ot 16 ianvaria 2020 g. po delu № 2-141/2019 [Decision of the Central District Court of Simferopol (Republic of Crimea) No. 2-141/20192-2805/20182-8/2020 2-8/2020 (2-141/2019; 2-2805/2018;) M-2737/2018 M-2737/2018 Dated January 16, 2020 in Case No. 2-141/2019]. Sudebnye $i$ normativnye akty $R F$ [Judicial and regulatory acts of the Russian Federation]. URL: http://sudact.ru/ regular/doc/Ks0XPWiS1b6W/ (accessed 1 April 2021).

20. Semeinyi kodeks Rossiiskoi Federatsii ot 29.12.1995 № 223-FZ (red. ot 04.02.2021) [Family Code of the Russian Federation of December 29, 1995 No. 223-FZ]. Rossiiskaia gazeta, 1996, 27 Jan. (no.17). 


\section{ВОПРОСЫ ЧАСТНОПРАВОВОГО РЕГУЛИРОВАНИЯ}

\section{Information About the Author}

Natalia A. Ablyatipova, Candidate of Sciences (Jurisprudence), Associate Professor, Honored Lawyer of the Republic of Kazakhstan, Department of Civil Law, Russian State University of Justice (Crimean Branch), Pavlenko St / Studencheskiy Lane, 5/2, 295006 Simferopol, Russian Federation, ve_na2014@mail.ru, mail@crb.rsuj.ru,https://orcid.org/0000-0002-4579-3871

\section{Информация об авторе}

Наталья Айдеровна Аблятипова, заслуженный юрист Республики Казахстан, кандидат юридических наук, доцент кафедры гражданского права, Российский государственный университет правосудия (Крымский филиал), ул. Павленко / переулок Студенческий, 5/2, 295006 г. Симферополь, Российская Федерация, ve_na2014@mail.ru, mail@crb.rsuj.ru, https://orcid.org/0000-0002-4579-3871 